\title{
Crisis y educación ambiental para la sustentabilidad: retos a los procesos formativos del profesorado ${ }^{1}$
}

\section{Crisis and environmental education for the sustainability: challenges to the teachers formative processes}

William Manuel Mora Penagos

Profesor de la Universidad Distrital Francisco José de Caldas. Facultad de Medio Ambiente y Reaursos Naturales. Ingeniería Forestal. wmora@udistrital.edu.co

Recibido: 30-05-2009

\section{Resumen}

Contextualizada la actual situación de crisis mundial, que destaca la variable ambiental como trasfondo de causas y consecuencias de ésta, la presente comunicación intenta mostrar la necesidad de una educación ambiental pertinente, su articulación a un proceso formativo de docentes que sea coherente con esos retos y la posibilidad de trabajar unos contenidos formativos sustentado en competencias básicas ambientales.

\section{Abstract}

The current global cisis has been contextualized and it highlights the environmental variable as the background for its causes and consequences. This proposal aims at presenting the need for a suitable environmental education, its link to teacher education process which might be consistent with the challenges and the possibility of working different contents based on basic environmental skills.

\section{Palabras Clave}

Crisis ambiental, Educación para la sustentabilidad, Enseñanza de las ciencias, ambientalización curricular, competencias ambientales, formación docente, contenidos ambientales.

\section{Key Works}

Environmental crisis, Education for Sustainability, Sciences Teaching, Environmental Curriculum, environmental skills, teachers education, environmental contents.

\section{Problemas ambientales globales: La educación para la sostenibilidad}

Desde finales del siglo pasado ha venido aumentado la convicción general de estar en un periodo de la humanidad de verdadera crisis civilizatoria y cultural de la modemidad tecno desarrollista y consumista (Ángel, 1995; Caride y Meira, 2001; Leff, 2002) asociada a los procesos de globalización de la economía, del conocimiento, de la información y de la geopolítica, que han conducido a un "pensamiento únicd" y a una "sociedad del riesgd" (Lujan y Echevernía, 2004). La "verdad incomodd" del cambio climático, el incremento de fenómenos de desigualdad entre Norte y Sur (ricos y pobres), el aumento del fundamentalismo político y religioso asociado a la carrera armamentista (especialmente a nivel nudear y bioquímico), y las actuaciones especulativas de las

${ }^{1}$ Ponencia resultado del Proyecto: 019-2006. Financiado por el Centro de Investigaciones y Desarrollo Científico- Universidad Distrital Francisco José de Caldas. 
grandes bolsas de valores (que han llevado al mundo a la actual crisis financiera global con desequilibrios macroeconómicos y pérdida de millones de empleos), amenazan la igualdad, la paz social y el medio ambiente, generando un problema público de miedo social al futuro, que algunos catastrofistas y apocalípticos han aprovechado para anunciar el acercamiento al punto de no retorno o de estado inevitable de extinción de la especie humana y de toda forma de vida en el planeta Tierra.

Para algunos expertos la solución no está en reactivar el crecimiento económico fundamentado en el consumismo (con el consiguiente y tradicional impacto depredador al medio ambiente), sino en aprovechar el momento histórico para introducir un nuevo tipo de desarrollo (de crecimiento cero) fundamentado, por ejemplo, en el principio de biomímesis o ecoefectividad que imita la economía ádica natural de los ecosistemas (Riechmann, 2006); dando la oportunidad de aparición a un modelo viable de sostenibilidad que articula Economía Verde y Desarrollo Humano, que propenda por nuevas tecnologías de energía renovable, de eficiencia energética y alimentaria, para así disminuir al mismo tiempo nuestra huella ecológica y reanimar la economía global (OEI PNUMA, 2009). Hay que decir que buena parte de las propuestas ante la crisis global no han desdeñado el anterior planteamiento; así en la Carta de la Tiena, promulgada durante la cumbre de Rio de Janeiro en 1992, asume un compromiso con un desarrollo sostenible compatible con los recursos disponibles (limitados, finitos y mal repartidos) y con la conservación del medio ambiente, estableciendo como objetivo fundamental restaurar y proteger la tierra como hogar seguro para la humanidad y toda la comunidad viviente, para lo cual se dirigió a las distintas culturas, religiones y grupos humanos haciendo un llamando a la interdependencia global y responsabilidad universal, a la alianza entre gobiemos, sociedad civil y empresas como mecanismo para la gobemabilidad efectiva; viendo la conveniencia de integrar las dimensiones ético - social, científica y económica, como bases para generar acciones hacia el respeto y aidado de la comunidad de la vida; la integración ecológica; la justicia social y económica; la democracia; la no violencia y la paz (Novo, 2003).

Las soluciones a la crisis global, que van ganando mayor consenso, reconocen que los problemas ambientales son fundamentalmente problemas del conocimiento y de la educación (globales / locales) que van más allá del aprendizaje sobre el medio, y son propios de una "complejidad ambiental" (como proceso de hibridaciones epistemológicas y ontológicas) sobre la comprensión del mundo y del ser (Leff, 2000; Garća - Díaz, 2004), en tomo a la construcción de las relaciones sociedad - naturaleza que requiere esencialmente de una visión sistémica, compleja, cútica, constructivista y hermenéutica, para su comprensión. Bajo citerios sistémicos y complejos se ha reclamado la integración epistemológica entre las ciencias naturales con las ciencias sociales y otros tipos de conocimientos (ancestrales, religiosos, populares, etc.) en un diálogo de saberes que permitan una formación para la comprensión y participación en la solución a este tipo de problemas, todos ellos de naturaleza compleja (Leff, 2002), en un contexto planetario en emergencia que requiere que todos nos involucremos en salvar la nave espacial (Tierra) en que viajamos (Vilches y Gil, 2003).

Las Naciones Unidas ha planteado la "Década de la Educación para el Desarmollo Sastenible (2005-2014)", -de ayya promoción es responsable UNESCO-, defendiendo un entramado de medidas tanto tecnológicas, políticas, y educativas, como respuesta al hecho de que gran parte de la ciudadanía y sus representantes políticos no han hecho eco de la necesidad de integrar la perspectiva del desarrollo sostenible en todos los niveles de la sociedad, a fin de convertir a la educación en un agente para el cambio, por lo que habría que implicar a todos los sectores, desde los responsables ministeriales y de las universidades a los profesores y estudiantes, impulsando a la vez medidas oficiales (de cambios aurniculares, promoción de aursos para la formación docente desde los centros de profesores, las consejerías, las universidades, etc.). 
La educación para la sostenibilidad convoca a que las propuestas curriculares deban ajustarse y reformarse no como algo que se adiciona sino que se debe integrar mediante un proceso de ambientalización curricular o de indusión de la dimensión ambiental al culríaulo de manera innovadora y global que aparece asociada a todos los campos disciplinares de conocimiento y no a uno en concreto, e impregna a todas las actividades de las instituciones escolares, para lo aual la formación permanente del profesorado es fundamental. Si bien no existe consenso generalizado sobre los principios y metodologías a integrar en los procesos de ambientalización curricular y de selección de contenidos de enseñanza consideramos que ellos dependen necesariamente del contexto teórico desde donde se mueven las distintas corrientes de educación ambiental (Mora, 2007), y donde los planteamientos de la cartografía propuesta por Lucie Sauvé (2004) podrían ser de gran utilidad.

A las universidades y a las facultades particularmente formadoras de docentes se les convoca a ser coherentes con su articulación a la solución de los problemas planetarios, ambientalizando y haciendo flexibles sus currículos bajo miradas inter y transdisciplinarias que hagan posible la formación de sus egresado capaces de asumir responsabilidad en sus actuaciones por lo que se requiere una formación en educación ambiental para la sustentabilidad por lo que el papel docente se transforma del dictar dase al diseño de espacios de aprendizaje en un contexto de transición de una cultura de trabajo en el aislamiento en el aula de clase y de su individualismo a la responsabilidad en el diseño curricular de forma colectiva entre pares y su puesta en práctica respetando los principios formativos institucionales y del curríalo de cada carrera (Mora, García y Mosquera, 2004).

Sin embargo, existen fuertes críticas que ven detrás de la inclusión de las ideas de sostenibilidad en el programa de la Década, un esquema de pensamiento estrecho y pobre para aspirar a ser un proyecto educativo y de sociedad, pues se cree que se dedicada menos a hablar de educación y más del aprendizaje de conocimientos (Sauvé, 2006) al intentar induir en un mismo concepto la educación global, la educación económica, la educación para el desarrollo, la educación multicultural, la educación para la conservación, la educación al aire libre, la educación intercultural, la educación para la igualdad de sexos, la educación para el consumo, la salud y la paz, como también componentes de disciplinas tradicionales, como la educación ćvica, la ciencia, la geografía, entre otras" (Leal, 2009). Por otro lado la expresión «educación para la sostenibilidad» pareciera sustituir el concepto de "educación ambiental", aunque algunos autores han querido mitigar esta situación de amenaza, proponiendo el de "educación ambiental para el desarrollo humano sustentable"; sin embargo es de adarar que la propuesta de la educación para la sostenibilidad se fundamenta en una trayectoria histórica de más de tres décadas de una «educación ambiental como una genuina educación para el desarrollo sostenible» (Novo, 2009).

\section{Las problemáticas ambientales locales: el caso educativo Colombiano}

Desde la primera globalización iniciado en el siglo XV con la conquista europea y luego con la globalización de las ideologías economicistas tanto marxista y neoliberal, las problemáticas ambientales en Colombia han estado asociadas a problemas de crisis intema, de violencia y odio, presentándose en las últimas décadas una intensificación por su vinculación al narcotráfico como financiador de grupos de delincuencia organizada, guerrillas y paramilitarismo que ha implicado destrucción de los ecosistemas y de insostenibilidad general. Ante esta situación se redama una tercera globalización: la de la complejidad e interdisciplinariedad (Carizosa, 2003) para crear escenarios de consenso y de modelos de solución, que implicaría no sólo lo político sino su articulación en equilibrio con lo económico, ecológico y ético para buscar la reconciliación, en un proceso de cambio que requieren la ayuda de los países que han sido corresponsales de la situación en que vive el país. Carrizosa (2003) plantea que para construir una tercera globalización de la cultura compleja y solidaria se requiere superar como obstáculos: la retórica (acerca del 
desarrollo sostenible), la corrupción (que hace prevalecer los intereses individuales sobre los sociales), la incoherencia (que lo disgrega todo), la inoportunidad (por los modelos de gestión inaplicables), complejidad (del medio físico-biótico, y la diversidad del medio socio cultural crean condiciones de incertidumbre y riesgo), la ineficiencia, la discontinuidad (de los proyectos y actividades), y la falta de concreción (que permita no quedarse en las ideas sino proseguir a los hechos).

En Colombia la Constitución Política de 1991 ha generado una normatividad que fomenta una educación para la cultura ambiental en todos los niveles educativos, orientada a la protección del ambiente y el derecho a un ambiente sano. A partir de los planteamientos constitucional se ha elaborado la Política Nacional de Educación Ambiental (MMA-SINA, 2002) que establece la obligatoriedad de induir la dimensión ambiental en los niveles educativos básico y medio la cual ha estado asociado a los Proyectos Ambientales Escolares (PRAES) como eje transversal en el marco de los Proyectos Educativos Institucionales PEI, vinaulados a la solución de la problemática ambiental particular de una localidad o región (Torres, 1996), lo que ha demandado de las facultades de educación retos en la formación inicial y permanente de los docentes tanto de ciencias naturales como sociales; retos que en muchos casos no ha sido atendida en los procesos formativos que se ofrecen. El sistemismo, la interdisciplina (abiertos a otras epistemologías y axiologías distintas del área ecológica o del área ética y moral), la gestión (en contacto con los organismos e instituciones encargados de la gestión ambiental), la ciudadanía (formado en actitudes y valores que permitan construir ciudadanos éticos y responsables), y el énfasis en el trabajo de campo con sentido de pertenencia en lo local y regional son los retos particulares en los procesos formativos de los docentes que trabajan en la educación ambiental, y que en las propuestas curriculares formativas muchas veces aparecen desintegradas 0 ausentes.

Por otro lado, con la generación de los Estándares Básicos de Competencias para la educación básica y media Colombiana, que indican las acciones de pensamiento y de producción en relación con las responsabilidades que como personas y como miembros de la sociedad se deben asumir auando se conocen y valoran críticamente los descubrimientos y los avances de las ciencias, el MEN (2004) ha querido acercar las ciencias naturales a las ciencias sociales intentando promover una educación crítica y ética, tolerante con la diversidad y comprometida con el medio ambiente, constituyendo un puente para crear comunidades con lazos de solidaridad, sentido de pertenencia y responsabilidad frente a lo público y lo nacional. Sin embargo los procesos de formación inicial y permanente del profesorado para participar el en desarrollo de currículos y de prácticas pedagógicas y didácticas en el aula parecen distar mucho de estar acordes con estas propuestas, por lo que nos preguntamos: cestán los docentes preparados para los retos de integración del conocimiento, de la interdisciplinaridad y del sistemismo, asociado a la resolución de problemas ambientales en un marco de sustentabilidad? ¿Son las propuestas formativas de docentes a nivel inicial y permanente que ofrecen las facultades de educación pertinentes a estas demandas? Responder a estas preguntas implica todo un proceso investigativo que escapa las intenciones de esta comunicación, por lo que aquí sólo intentaremos reunir cíticamente algunas fuentes para argumentar posibles procesos de cambio en los procesos formativos del profesorado de educación ambiental, iniciando con el planteamiento de las dificultades que parten de la falta de acuerdo sobre el conocimiento de la educación ambiental.

\section{La problemática de la educación ambiental}

Daniel Luzzi (2000) sostiene que la educación ambiental (EA) en las instituciones educativas formales se ha reducido, en la mayoría de los casos, a un tema más de los denominados "emergentes de la comunidad o, temas transversales" y de paso a un recetario dispuesto para todo tipo de inserción desde las más pertinentes hasta las más arbitrarias e irreflexivas; bajo esta redamación este autor no considera conveniente que la EA sea transversal a cada una de las áreas 
disciplinares, como lo son la lengua, las matemáticas o la educación en valores, y sostiene que la EA es más que ello, a la manera de una "infusiórt' pues obedece a una dinámica histórica de la educación de gran complejidad en diálogo entre las concepciones del conocimiento, el aprendizaje, la enseñanza, la sociedad y el medio ambiente, un eje natural de convergencia disciplinar que da auenta de la problematización de las diversas disciplinas en relación con un eje que las irradia, transforma y retotaliza y de la reorganización de las prácticas actuales de aprender a aprender la complejidad de la realidad, por lo que la EA redama la producción de un saber ambiental que problematice las distintas disciplinas, generando nuevos conocimientos, nuevas maneras de interpretación y la comprensión de la realidad al replantearse la responsabilidad social y la complejidad del presente y futuro planetario. Así la dimensión ambiental lejos de incorporarse transversalmente como un área de conocimiento más, pasa a constituirse en el centro de análisis de la cuestión educacional, internalizada a través de un diálogo de saberes que excede y sobrepasa el campo de la racionalidad científico - tecnológica, construyéndose en relación con las condiciones sociales, aulturales, los procesos productivos, etc.

En complemento y siguiendo los planteamientos de Gutiérrez (2002) y García-Díaz (2004), la EA atraviesa por una serie de problemas estructurales que determinan sus prácticas y que parecen no estar resueltas en el presente:

> La EA es un ámbito de conocimiento en el que no hay un paradigma unificador establecido, predominando la heterogeneidad, la controversia y las discrepancias que se reflejan en una gran confusión teórica y metodológica, lo que no permite la formación de un cuerpo de conocimiento consensuado en una comunidad académica propia, lo que dificulta la investigación (mayoritariamente descriptiva).

> El modelo inicial de corte naturalista centrado en la comprensión del medio, un modelo predominante ambientalista y positivista tendiente a proteger el medio, y una visión emergente próximo al desarrollo sostenible y el cambio social, han generado, polaridades unas dirigidas al cambio conceptual y al cambio de actitudes y valores; y la otra dingida a la práctica, muchas veces sin una marco teórioo de referencia lo que degenera en visiones tecnicistas y activistas de la EA.

> Hay muy pocos grupos de investigación integrados interdisciplinarmente que se dedican a la EA, aunado a que la preocupación por la EA ha sido más patente en colectivos e instituciones ajenas al campo educativo, que de las Facultades que forman al Profesorado lo que supone graves carencias en sus procesos formativos.

$>$ En la medida que se integran cada vez profesionales del área social se ha ganado en la perspectiva crítica y la integración de la EA con la educación global, el desarrollo sostenible, la educación en valores, pero a su vez se ha venido perdiendo terreno la perspectiva ecológica en la formulación de los contenidos ambientales en la medida que los aspectos económicos, políticos, sociales, etc, aparecen como exigencia en los currículos.

> Insuficiente valoración de áreas como la sicología ambiental, la didáctica de las ciencias, e induso de la pedagogía.

> En la EA actual se da una paradoja, al mismo tiempo que se rechaza la concepción positivista del mundo (ya que los disaursos invitan a adoptar un pensamiento complejo y crítico) se admiten posiciones positivistas y conductistas respecto al modelo de aprendizaje. Se requiere abrir un debate sobre en qué momentos y según qué fines es más adecuado basar las estrategias de intervención en modelos asociacionistas o en modelos constructivistas, pues esta confusión viene frenando el desarrollo de la EA.

> En el campo de la EA no hay un desarrollo adeauado del ámbito didácico, de forma que apenas si hay discusión sobre la naturaleza epistemológica de los objetivos, contenidos y sobre su organización y secuenciación. Las revistas de prestigio internacional al igual que muchos de los investigadores reconocidos en EA apenas si le dan importancia al ámbito didáctioo de la EA.

> En la tradición de la EA si bien ha tenido incidencia importante en la formulación y organización de los contenidos escolares no lo ha sido tanto en la relación de estos contenidos con respecto 
a las estrategias didácticas de enseñanza que se pueden vincular particularmente con aquellas que se fundamentan en los procesos constructivistas del aprendizaje del estudiantado, como de la formación inicial y permanente del profesorado de EA.

Aunque las situaciones de aprendizaje propuestas en EA interesan a los alumnos porque ellas están relacionadas con su realidad concreta, pudiendo ligar el conocimiento a la acción y sentir que ellos pueden participar del cambio social, el hecho que la EA la mayoría de las veces esté a cargo exdusivamente de los profesores de ciencias naturales y en particular del profesorado de biología genera muchas dificultades de articulación de las visiones sociales y humanísticas.

La mayoría de las actividades de EA han encontrado distintos obstáculos e inercias que impiden la eficacia de sus propuestas. Por ejemplo, Vilches y Gil (2003) dicen que el profesorado ha arestionado la efectividad de cualquier acción de EA sustentados en tres razones:

$>\quad$ La primera se refiere a que la responsabilidad de la situación actual no recae en las personas si no en "el poder", es decir, en los políticos y, sobre todo, en el complejo financiero - industrial transnacional.

> La segunda, que lo que puede hacer cada cual para mejorar la situación es irrelevante frente a las acciones de la gran industria.

> Por último, que las acciones educativas son ineficaces y que la mayoría de los ciudadanos mantienen comportamiento depredadores, sin atender a explicaciones y llamamientos.

\section{La Educación Ambiental y su relación con la Enseñanza de las Ciencias}

Sanmartí, (2004) nos dice que la EA es un movimiento curricular nacido con este nombre en los años 60, aunque con una tradición más antigua que el campo de la enseñanza de las ciencias, que actualmente entronca por sus objetivos con alguna de las corrientes $C / T / S$; y que a pesar de esta vinculación, la didáctica de la EA ha tenido un desarrollo autónomo, con marcos teóricos de referencia distintos a los de la didáctica de las ciencias. Este hecho ha comportado que la evolución de los dos campos no haya sido paralela y que los discursos hayan estado a menudo bastante alejados, conllevando una serie de prevenciones que dificultan el trabajo colectivo.

Sauvé (2004) presenta algunos comentarios, obtenidos con profesores de ciencias, que generan un imaginario que dificultan la posibilidad de articular Educación Ambiental y Enseñanza de las Ciencias:

> La EA amenaza la integridad de las disciplinas científicas ofrecen un contexto de vulgarización de nociones abstractas. Se corre el riesgo de vaciar de la enseñanza de las ciencias su contenido disciplinario. Si se introducen las problemáticas ambientales por ejemplo, no se hace química. Educar en los valores, eso no es ciencia.

> La ciencia utiliza un método particular, es decir un método experimental, hipotético deductivo: se trata de entrar en contacto directo con la realidad, de observar, de cuestionarse, de emitir hipótesis, de verificarlas. A menudo, las actividades en EA eliminan el contacto con el objeto de aprendizaje $y$ se otorgan un carácter seudo -científico. Se limita a buscar informaciones en documentos, sin verificar la exactïtud; se da una pretendida garantía científica, sin estimular el espíritu crítico.

$>$ Existe un gran parecido entre el proceso científico y el proceso de resolución de problemas: observación del medio, problematización $y$ seguimiento del proceso de resolución. Esta convergencia puede ser ventajosamente utilizada para aproximar entre ellas la EA y la enseñanza de las ciencias.

> Hay un peligro en reducir la EA al campo de la enseñanza de las ciencias, donde paradójicamente la EA es a la vez reivindicada como objeto propio y legítimo y percibido como una especie de « oveja negra » que plantea problemas. Para algunos, el problema es el del 
riesgo de desnaturalizar la enseñanza de las ciencias, para otros el problema es el de las condiciones actuales de enseñanza que no permiten desplegar adecuadamente la EA.

$>$ Si se limita la EA a la enseñanza de las ciencias se pierde el sentido. La EA no puede contentarse con un enfoque científico de las realidades biofísicas.

\section{La Educación Ambiental y sus relaciones con la gestión ambiental}

La mayoría de enfoques de EA están separados tanto de la Gestión como también del trabajo didáctico y no trascienden, más allá de ser actividades desconectadas de estos dos factores, la mayoría de actividades en EA tienen el único fin de cumplir con exigencias normativas pero sin trascender a respuestas efectivas de gestión o de aprendizajes en las aulas. Para muchos, incluso investigadores como lo vimos en el apartado anterior, la EA es un campo históricamente poco maduro y poco definido (no sólo por su nacimiento, reciente en los años 70 s del siglo $X X$ ), por lo que no se admite, la didáctica de la EA (ya que piensan que lo didáctico centrańa los problemas de EA al aula escolar exdusivamente y alejaría la escuela de las actividades de participación en la gestión ambiental), otros han delimitado los campos de acción de la EA sólo a la gestión, negándose a aceptar por ejemplo, el periodismo ambiental como campo de la EA, de igual manera se confunde la participación de una educación ambiental formal y no formal; pareciera que la publicidad ha permitido más avances en lo no formal, mientras que en lo formal que estaría a cargo por ejemplo de la didáctica, está muchas veces desvinculados de la EA no formal y de la gestión ambiental, también para otros la EA formal tiene su contexto sólo en la Educación Básica y Media y no en la educación superior, como se puede ver en la casi ausencia de la ambientalización de sus auríalos (Junyet et al, 2003; Mora, 2007).

Benayas, Gutiérrez y Hemández (2003) sostienen que las intervenciones educativas ambientales no son de gran utilidad si no van acompañadas de medidas de gestión eficaces así muchas de las campañas de sensibilización ambiental generan la necesidad de un comportamiento espeáfico sin que existan las infraestructuras apropiadas para responder a las demandas que implican, muchas veces incentivadas por intereses políticos o por la moda y actualidad de los temas ambientales. Un ejemplo es el caso de generar campañas de reciclaje para luego enterarse que en realidad se ha perdido el tiempo seleccionando y dasificando la basura, pues en los rellenos sanitarios se vuelve a mezdar la basura ya que no existe infraestructura para los procesos de aprovechamiento, lo que genera actitudes negativas, desmotivación y pérdida de credibilidad irreversibles. En síntesis esta es una EA que no guarda contacto y responsabilidad con la realidad de los problemas. El interés, entonces, está en reconocer nuevas tendencias que superan la visión del ambiente en tanto protección y conservación, para asumir la gestión integral, con una perspectiva ecológica del desarrollo urbano regional sostenible, donde lo sistémico se evidencia como la apuesta que puede hacer realizable tal tendencia.

Lo que parece daro es que una gran diversidad de actividades educativas podrían estar en el ámbito de lo Ambiental aunque no se pueda concebir como una nueva disciplina ya que su naturaleza estaría más en lo inter y transdisciplinar. Diversos autores han discutido sobre la idea de considerar a la EA como un eje que permita unir los diversos conocimientos disciplinares, el reto es complejo ya que más allá de su bondad discursiva un sistema transversal de enseñanza debe luchar con inercias disaplinarias que se resisten a la integración. Por otro lado, resulta daro que el ejercicio no puede consistir en tomar fragmentos de cada disciplina e integrarlos forzadamente y que la organización del tiempo escolar no contempla la incorporación de esta dimensión.

Al poco desarrollo del campo de la EA y su articulación con la gestión y la didáctica de la EA como campos académicos se adiciona el poco acuerdo de su campo de actuación de la EA; así Benayas, Gutiérrez y Hemández (2003) proponen como ámbito de la EA las siguientes actividades que dependen del tiempo de intervención que va desde segundos hasta años de intervención, 
progresivamente como se muestra en la siguiente lista: Publicidad Ambiental, Información Ambiental, Interpretación Ambiental, Educación No Formal Ambiental, Educación Formal Ambiental, Formación y Capacitación Ambiental y Partiajpación Ciudadana.

Los niveles de intervención en el proceso educativo son también diversos. Por un lado, en el ámbito de la Educación formal existen espacios que no pueden ser desatendidos, como el diseño curricular y la formación inicial y permanente del profesorada, haciéndose necesaria una oferta educativa más amplia en los niveles medio y superior. En el caso de la educación no formal resulta fundamental la caracterización de los diversos espacios recreativos y culturales, el uso de los medios de comunicación, el fomento de la participación social y la vinculación entre los programas de trabajo de las organizaciones no gubernamentales. Evidentemente el cabal cumplimiento de estas metas entraña dificultades de muy diversos tipos: quizá la más importante es la percepción, tan extendida en la sociedad, de que un problema ambiental es en realidad un asunto ecológico que puede ser resuelto a través de acciones consignatarias como el no tirar la basura o sembrar un árbol. Este activismo, si bien ha jugado un papel en la sensibilización de la sociedad, no tiene efectos significativos en nuestras pautas culturales debido a la falta de concreción de las acciones propuestas.

\section{Educación Ambiental y currículos formativos}

Al igual que existen límites difusos entre disciplinas y saberes que participan en la resolución de problemas ambientales, de igual manera el campo teórico en construcción de la EA, se encuentra impregnada por distintas perspectivas; muchos proponen una visión transdisciplinar articulada a Temas Transversales, y para algunos, transformada en Educación en Valores para el Desarrollo Sostenible, sin embargo es posible encontrar una serie de matices con ciertas diferencias, como es el caso de las siguientes perspectivas:

> La Educación Global. Para Selby (1996) cuatro son las dimensiones interrelacionadas para la estructuración de una educación global: la dimensión espacial, la dimensión temporal, los temas globales, y (en el centro de las interacciones) el mundo interior (el Yo); estas dimensiones permitirían diseñar curníaulos que nos proyecten a una educación para el futuro que sustente mutuamente la persona y el planeta, al formarse una serie de conciencias de los estudiantes para pensar en forma sistémica: conciencia de perspectiva que permita reconocer que nuestras visiones de mundo no son universalmente compartidas, conciencia de la salud del planeta y de sus condicionamientos globales entomo a los derechos humanos, conciencia de la participación y de la preparación desde habilidades sociales y políticas para la toma de dediciones democráticas en los niveles glocales, y conciencia y valoración de los procesos de aprendizaje continuo a lo largo de toda la vida.

A su vez Yus, (1997), parte de una concepción de la realidad global, sistémica, y compleja, planteando como ejes: la globalización de la aultura, la educación integral de las personas, la organización democrática de la escuela y el compromiso de la educación con la problemática socio - natural, para un pensamiento solidario que permita afrontar los problemas y crisis del mundo actual y futuro. Este enfoque de educación global se ha originado de propuestas fundamentadas en la transversalidad del aumíallo y de los temas transversales (que son entendidos como organizadores de contenidos interdisajplinarios a manera de núdeos de interés a nivel educativo que no tienen una ubicación precisa espacio / temporales en el aumíaulo y que carecen de una epistemología espeáfica), sin embargo este enfoque es criticado por la falta de un sistema conceptual de referencia que organice e integre los conocimientos (Porlán y Rivero, 1998), por presentarse de manera individualizada como un grupo de temas inconexos y optativos en los aurríaulos. Una solución que ha planteado Yus (1997) es transversalizar los transversales, globalizando la educación en un sistema de temas relacionados con la salud, el medio ambiente, y 
la sociedad, los cuales induirían otros como: la paz, la calidad de vida, y la solidaridad; sin embargo queda en el fondo una imagen de ser una propuesta que podría generar el peligro de conducir al camino de la moralización y no tanto hacia el pensamiento sistémico, autónomo y divergente.

> Los movimientos $C / T / S / A$, tendientes a la alfabetización en ciencia - tecnología y ambiente para todas las personas (que contribuya en una cultura ciudadana para la toma de decisiones acerca de los problemas a los que se enfrenta la humanidad, la formación de espíritu crítico, y principalmente para el disfrute personal) (Acevedo y otros, 2003; Gil y Vilches, 2003; Cañal, 2004) se sitúan más en la transformación del currículo de las ciencias (naturales / sociales), mientras la educación global y la transversalidad afectan todo el aurnículo escolar. García Díaz (2006) previene de la tendencia pendular de este enfoque de moverse en dos reduccionismos: de los contenidos de la ecología -como ciencia compleja y como cosmovisión(tanto de los sistemas naturales como de los humanos), a una centrada en los aspectos sociales, ideológicos y eticistas, que ignoran la importancia de las ciencias de la naturaleza; y argumenta que no se trata de adicionar factores nuevos a la naturaleza de las ciencias, sino de superar las concepciones mitificadas del trabajo cient́fico como una actividad neutral, descontextualizada, ajena a intereses y conflictos, en la que es importante asumir posiciones críticas ante la racionalidad económica dominante; en fin, una educación de las ciencias que además de facilitar la construcción del mundo sea un instrumento para comprender y actuar en él.

> La perspectiva socio-crítica (Caride y Meira, 2001; Porlán, 2001; Garáa-Díaz, 2004), tiene asiento en la articulación entre las ciencias naturales, las ciencias sociales, las ciencias ambientales como la ecología, los saberes filosóficos, y las ciencias psicopedagógicas y didácticas; en la trasformación de la escuela y la sociedad. Donde se critica muchas de las visiones anteriores que admiten de alguna manera que todos somos responsables de la crisis ambiental y social; ignorando que la responsabilidad en últimas habría que buscarla en la naturaleza de las estructuras sociales y económicas dominantes como de las ideologías que las sustentan. En este enfoque muestra el curnículo global más como integración de saberes complementarios que se ponen en juego en la solución de problemas escolares en los que se hace fundamental trabajar conceptos metadisciplinares, así "...la ciencia disciplinar no es el objeto último de la educación ni el referente exclusivo para la determinación del conocimiento escolar. Los problemas que se deberían trabajar en la escuela son los problemas relevantes para los ciudadanos, no los problemas científicos, de forma que no se trata de acercarse a lo social desde la ciencia, sino a la ciencia desde lo social", "el conocimiento escolar es una transición desde formas simples del pensamiento hacia otras más complejas", "el conocimiento metadisciplinar alude a conceptos como sistema, cambio, interacción o diversidad, a procedimientos propios del trabajo de problemas complejos $y$ abiertos, $y$ a valores relativos a una visión relativizadora, autónoma y solidaria del mundo". Interpretando a Garća - Díaz (2004) se podría pensar que la integración debe cuidase de no generar un nuevo reduccionismo simplificador al tratar de fusionar apresuradamente diversos campos en uno sólo, llámese educación global o educación para el desarrollo sostenible; 10 importante es la complementariedad e integración entre lo general y lo espećfico a la hora de formular contenidos de EA y que sean una construcción abierta, flexible, y progresiva de problemas socio - ambientales como eje articulador de los contenidos en un contexto cultural de 10 científico-técnico y lo metadisciplinar (como marco de referencia en el diseño y programación de los diferentes niveles de complejidad de los contenidos).

\section{Retos para la formación de formadores}

Como ya se ha dicho, la situación de emergencia planetaria hace que la dimensión ambiental sea parte fundamental de los procesos formativos en todos los niveles educativos y parte central de 
las actividades del desarrollo profesional docente; sin embargo ambientalizar los programas aurriculares y los contenidos de enseñanza requieren de un proceso de apertura de los paradigmas teóricos, las barreras institucionales $y$ los intereses disciplinarios, si se quiere apuntar a reformas más allá de la buena voluntad o de las dedaraciones de papel.

La Universidad no puede educar en valores que no tiene ni práctica, no puede pregonar la sustentabilidad, ni la inter y transdisciplinariedad, ni la multiculturabilidad, si ella no es sustentable, sino respeta la diferencia, sino se desarrolla entre sus académicos una actitud inter y transdiciplinar. Es fundamental una nueva estructuración de las universidades que superen formas de organización de las dásicas facultades monóliticas, unidimensionales y de yuxtaposición de monodisciplinas encorsetadas rígidamente en compartimentos departamentales que no estimulan la interdisciplinariedad ni la flexibilidad, requeridos para la solución de problemas complejos de naturaleza ambiental; movilizándose a la creación de proyectos curriculares que convoquen distintas conocimientos y saberes provenientes de distintas facultades en un dialogo entre lo natural con lo social, estableciendo puentes entre distintas disciplinas, profesiones y oficios. Para lo aual se requiere un cambio de actitud del profesorado formador de formadores en ciencias que superen la enseña de la historia de las ciencias naturales y la enseñanza de las monodisciplinas, y se interesen por los problemas de las tecnociencias en la sociedad y los problemas globales ambientales.

Las redamaciones formativas del profesorado no sólo se dan en el plano de la generalidad de lo ambiental, (que se sustentan en la idea que si los docentes no entienden la crisis global y ambiental no pueden preparar a sus estudiantes para ella y para que sean ciudadanos del mundo), sino también se dice que si no integran al entendimiento la sociedad del conocimiento (o sociedad del aprendizaje) con las nuevas formas de la comunicación propias de la era digital, tampoco tendrían una formación docente competente. Cada vez hay un mayor consenso en tomo a la idea de que las nuevas tecnologías de la información anuncian el fin de la enseñanza universitaria tal como la conocemos, experimentado un cambio hacia una comunidad académica virtual, es decir una comunidad en la que el profesorado aprende e intercambia ideas electrónicamente; así las nuevas tecnologías digitales señalan el inicio de un mundo nuevo, más dinámico y más interactivo, con nuevos riesgos y desafíos, del mismo modo como la imprenta de Gutemberg, marcó el inicio de la modernidad.

El aprendizaje se ha convertido en algo permanente como respuesta a un mundo en constante cambio y competitividad, necesitando de la innovación en el campo productivo y personal, lo que hace que gran número de egresados redamen una educación permanente más allá de un tútulo universitario y si de ganar en competencias, que les permita "recidar" sus aprendizajes mediante educación postgradual y de formación a lo largo de toda la vida, resolviendo problemas en diferentes situaciones e intensiones desde diversas culturas e idiomas. En este contexto de retos educativos las instituciones y el profesorado están avocados a diseñar nuevos enfoques sobre la enseñanza creando mejores entomos educativos centrándose en el estudiante y no en el profesor. Así, "el mayor desafío con que deberán enfrentarse muchas universidades en la próxima década y los años siguientes consistirá en cambiar los entornos de aprendizaje" (Hanna, 2002).

En este escenario el aprendizaje reemplaza la enseñanza de contenidos únicamente conceptuales, o por lo menos le cambia su sentido, poniendo énfasis en capacidades de pensamiento de alto nivel, en la metacognición, en la comprensión, en la aplicación de inteligencias múltiples, en estrategias de aprendizaje cooperativo en tomo a la resolución de problemas socialmente pertinentes que demandan contenidos conceptuales y procedimentales, en el uso de amplia gama de formas de evaluación, utilización de las TICs. Estos requerimientos inían en otra dirección a la enseñanza tradicional basado principalmente en la dase magistral y también sería incompatible en buena parte con la educación a distancia que se centra en la experiencia personal de individuos aislados y dependiente de un instructor (así hallan interacciones interpersonales 
mediante redes de comunicación y comunidades virtuales), se redama la conexión entre estudiantes y docentes en forma de trabajo colaborativo en tomo a problemas reales y de contexto aprovechando el mundo de información disponibles en bases de datos y en la red.

Articulando las ideas expresadas en la sección anterior de este documento, se podría decir que: nuevas formas de enseñanza centradas en el aprendizaje, y la resolución de problemas de carácter socio ambiental, demandan una epistemología sistémica para la construcción del conocimiento. Esto significa convertir de nuevo la pedagogía y la didáctica en una profesión en la que hagamos de la docencia una misión social y una profesión creativa, en la que los docentes conozcan y se preocupen por su mundo a la vez que por su profesión reauperando su estatus y dignidad como unos de los principales intelectuales de la sociedad y no que sigan siendo los técnicos e instrumentos de otras personas que les diseñan los currículos.

\section{La Falta de integración de las funciones universitarias en la práctica docente del profesorado formador de formadores}

La cultura imperante de fragmentación de las funciones del profesorado formador de formadores (docencia, investigación y extensión) hacen que la producción en investigación del profesorado, muchas veces tenga poco que ver con la docencia que practican, la cual está confinada al ejercicio reproductivo de tradiciones académicas, en el que ser académico es ser investigador y contradictoriamente la formación académica profesional no se realiza desde los resultados de la investigación, y así se generan disputas entre los límites de los profesores que hacen investigación y los que únicamente hacen docencia. En algunos casos, la práctica docente es dirigida por un profesorado no vinculado con la investigación pedagógico / didáctica, y por otro lado, buena parte del profesorado al privilegiar la investigación sobre la docencia, se desliga la planeación curricular y las actividades de aula. También se puede afirmar que buena parte del profesorado que forma profesionales de otras áreas distintas a la educación, no asume la docencia como una actividad profesional y en consecuencia la considera como una rutina laboral desprovista de marcos teónicos, desconociendo el resultado de investigaciones en educación, lo que hace que se mantengan alejados de reflexiones colectivas para encarar la enseñanza de sus campos de formación básica (Clarke y Hollingsworth, 2002).

Si bien las investigaciones sobre la enseñanza en la educación superior comienzan a ser objeto de interés, particularmente en los años noventa del siglo XX, puede afirmarse que las problemáticas que la docencia en este nivel de educación llevan consigo, no han recibido la misma atención investigativa que los niveles educativos de la básica y la media. Lo anterior demuestra que en general las políticas investigativas en educación como también las tendencias de los proyectos de muchos grupos de investigación solo en los últimos años adquieren un interés particular por la formación pedagógica y didáctica del profesorado universitario, entre varias razones por las exigencias provenientes del proceso de acreditación de alta calidad. Hoy por hoy, para nadie es desconocido que los docentes son un factor decisivo en la calidad de la enseñanza universitaria, a igual nivel que lo son otros factores como: la organización, la dirección académica, los currículos y programas, los proyectos de investigación, las trasferencias y flexibilidad académica, como de las políticas de mejoramiento del desempeño docente universitario.

Como hemos encontrado en anteriores trabajos de investigación (Mora, García y Mosquera, 2004) las propuestas formativas docentes deberían tener en cuenta los siguientes elementos:

$>$ Si partimos que la mejor manera que encontramos para la formación docente es superar las actividades tradicionales de sumatoria de cursos de pedagogía, epistemología y sicología, debido a que se ha encontrado que dichos procesos no generan identidad ni compromiso con el contexto disciplinar de la pedagogía y didáctica y si generan estados de regresión, insatisfacción y prevención a futuros proceso de formación docente. 
> La formación del profesorado más exitosa es aquella en la que el profesorado no recibe únicamente información externa y se les toma como consumidores de los productos de la investigación didáctica sino aquella en la cual el profesorado se implica en procesos de aprendizaje en comunidad de docentes para solucionar sus propios problemas de aula y asume el papel de los expertos de investigación didáctica como asesores.

> El desarrollo profesional docente en lo pedagógico y didáctico podría contextualizarse en los procesos de investigación aurricular y en el sentido de dar auenta de su participación del diseño, aplicación y autoevaluación permanente con participación colectiva.

$>$ El desarrollo profesional podría ser entendido como un cambio en la didáctica de sus concepciones prácticas y formas organizativas de participación en las tomas de decisión y evaluación del diseño curricular.

> El permitir que aualquier docente que soliciten realización de estudios doctorales o de maestría en didáctica o pedagogía sean apoyados con igualdad de oportunidades no sólo aquellos que pertenecen a la facultad de educación, sino también a lo que están adscritos a las facultades de ciencias, ingenierías, tecnologías 0 artes.

\section{Formación en competencias ambientales}

La formación del profesorado en un contexto propio de las problemáticas socio-naturales requerińa un proceso inicial y permanente en tomo a posibles competencias ambientales. La finalidad que se persigue es que todos los egresados de las facultades universitarias (más allá de las dedicadas a la formación del profesorado), hayan adquirido competencias básicas para tomar decisiones y realizar sus acciones profesionales desde la perspectiva de la sostenibilidad, lo que hace necesaria una revisión integral de los aumíaulos, para que incluyan contenidos (cognitivos, procedimentales y actitudinales), metodologías y prácticas que preparen explícitamente en competencias sostenibilizadoras que se puedan especificar en el perfil de los títulos de las diferentes carreras.

Aunque el término 'competencia', resulta ser un término confuso, ambiguo y polisémico, sujeto a diversas interpretaciones y significados que dificulta el diseño de cualquier propuesta formativa de aurnículo universitario, se ha introducido con fines de intemacionalizar la educación superior asociados a: un aumento de la pertinencia de los programas educativos (acorde con los retos y problemas del contexto social, comunitario, profesional, organizacional y disciplinar - investigativo); gestión de la calidad de los procesos de aprendizaje de los estudiantes (evaluación de la calidad del desempeño y evaluación de la calidad de la formación que brinda la institución educativa); política educativa internacional (desde el Congreso Mundial de Educación Superior); movilidad (búsqueda de la movilidad de estudiantes, docentes, investigadores, trabajadores y profesionales entre distintos cidos de formación a nivel local e interno de cada universidad, a nivel nacional entre universidades pares, e internacional entre universidades que tienen convenios).

Una formación en competencias deseable podría estar en el marco de la complejidad y orientada hacia la formación integral teniendo en cuenta de los siguientes elementos dialógicos que permite mantener la dualidad en el terreno de la unidad, asociando críticamente dos términos a la vez complementarios y antagonistas: mundo de la vida / mundo del trabajo; individual / social; derechos / deberes; responsabilidad y ética pública / intereses privados; público - civil / económico - empresarial global; competitividad / cooperación - solidaridad; comunicación para la ciudadanía democrática / político - productivo; lo humano - antropocéntrico / lo ambiental - biocéntrico.

En este contexto hemos propuesto en la Universidad Distrital el siguiente concepto (Mora, 2008c): "Las competencias son procesos complejos (cognitivos / afectivos / aulturales) de formación integral (socio humanístico / laboral) que posibilitan a los ciudadanos resolver problemas en el mundo de la vida cotidiana y en el mundo del trabajo, en el contexto de los deberes $y$ 
derechos para del desarrollo humano, social y ambiental sostenibles, aportando a la construcción y transformación de la realidad de forma idónea y responsable; para lo aual se integran formativamente el saber ser, el saber hacer, y el saber conocer, teniendo en aventa los requerimientos específicos del entomo educativo y del proyecto ético de vida de cada persond'.

Aunque es posible plantear tres tipos de competencias; ciudadanas, básicas, y laborales, las competencias ambientales para la sostenibilidad las podemos dasificar como básicas y caracterizan a una persona formada para el uso inteligible de saberes fundamentales y de prácticas sustentadas en la interdisaip/inariedad, para poder enfrentar el ritmo con que se que producen nuevos conocimientos, informaciones, tecnologías, con visión sistémica y responsabilidad ética.

Aznar y UII (2009), como producto de la aplicación de encuestas a docentes universitarios españoles, proponen el siguiente listado de competencias básicas en términos de capacidades, dirigidas a los procesos formativos de distintas titulaciones universitarias, que podrían de ser de gran utilidad al diseñar los curríalos de los distintos espacios académicos.

\begin{tabular}{|c|c|}
\hline COMPETENCIAS & CARACTERISTICAS \\
\hline $\begin{array}{l}\text { Competencias cognitivas } \\
\text { (SABER): para la comprensión } \\
\text { crítica de la problemática socio- } \\
\text { ambiental global, nacional, } \\
\text { local. }\end{array}$ & $\begin{array}{l}\text { - capacidad de reconocer las diferentes formas de organización social y política y su } \\
\text { influencia en la resolución de problemas relacionados con la sostenibilidad. } \\
\text { - capacidad para integrar las diferentes dimensiones ambientales (social, cultural, } \\
\text { económica, política, estética, física, biológica) en la toma de decisiones } \\
\text { profesionales, } \\
\text { - capacidad de percibir lo global desde la acción local (comprensión transcultural), } \\
\text { - capacidad de reflexionar objetivamente sobre los modelos de comportamiento } \\
\text { individuales y culturales vigentes en la sociedad. }\end{array}$ \\
\hline $\begin{array}{l}\text { Competencias metodológicas } \\
\text { (SABER HACER): adquisición de } \\
\text { habilidades, estrategias, } \\
\text { técnicas y procedimientos para } \\
\text { la toma de decisiones y la } \\
\text { realización de acciones } \\
\text { relacionadas con la } \\
\text { sostenibilidad. }\end{array}$ & $\begin{array}{l}\text { - elaborar y aplicar indicadores de problemas relacionados con el desarrollo humano } \\
\text { ambientalmente sostenible; } \\
\text { - colaborar en la realización de auditorías ambientales; } \\
\text { - diseñar planes de acción contextualizados que incluyan acciones educativas para } \\
\text { fomentar los valores de la sostenibilidad, } \\
\text { - creación o modificación de actitudes que los desarrollen y la permanente } \\
\text { actualización de comportamientos que los apliquen; } \\
\text { - interactuar de forma interdisciplinar en la solución de problemas ambientales } \\
\text { relacionados con el ámbito académico-profesional, } \\
\text { - participar en la gestión ambiental de la comunidad local, } \\
\text { saber aplicar transversalmente las acciones relacionadas con el medio ambiente } \\
\text { natural y social derivadas de la toma de decisiones profesionales. }\end{array}$ \\
\hline $\begin{array}{l}\text { Competencias actitudinales } \\
\text { (SABER SER Y VALORAR). } \\
\text { Centrada en una ética de } \\
\text { derechos humanos de 1ra, 2da } \\
\text { y 3ra generación: a) } \\
\text { individuales que atañen a las } \\
\text { relaciones entre los seres } \\
\text { humanos b) sociales que atañen } \\
\text { a las relaciones entre los seres } \\
\text { humanos y las organizaciones } \\
\text { sociales, y c) ambientales, de la } \\
\text { paz y el desarrollo de los } \\
\text { pueblos y atañen a las } \\
\text { relaciones entre los seres } \\
\text { humanos, el resto de los seres } \\
\text { vivos. }\end{array}$ & $\begin{array}{l}\text { - capacidad de relacionar valores/comportamientos desde el conocimiento de las } \\
\text { creencias, valores y actitudes que subyacen en las relaciones que las personas } \\
\text { tienen con su entorno; } \\
\text { - capacidad de reconocer los modelos éticos que impulsan la toma de decisiones y la } \\
\text { realización de acciones relacionadas con el desarrollo sostenible; } \\
\text { - capacidad de reconocer las propias creencias, valores y actitudes en tomo a las } \\
\text { cuestiones relacionadas con la sostenibilidad; } \\
\text { - capacidad de empatí, compasión y solidaridad intra e intergeneracional; } \\
\text { - capacidad de situarse ante los dilemas ético-ambientales y razonar y justificar sus } \\
\text { posibles soluciones; } \\
\text { - capacidad de auto-motivación hacia comportamientos coherentes con los valores de } \\
\text { la sostenibilidad; } \\
\text { - capacidad de construir una ética personal para la sostenibilidad; } \\
\text { capacidad de prever las consecuencias de las decisiones tomadas (pensamiento } \\
\text { previsor); } \\
\text { capacidad de desarrollar el sentido de responsabilidad hacia las consecuencias de las } \\
\text { propias decisiones y acciones. }\end{array}$ \\
\hline
\end{tabular}

\section{Contenidos ambientales}

Para definir los contenidos ambientales no sólo es necesario tener claras las competencias formativas sustentadas en la resolución de problemas; también se requiere tener en una serie de principios y metas que permitan su diseño atendiendo a otros criterios complementarios como la

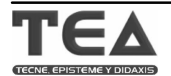


propuesta de tramas evolutivas de conocimiento atendiendo al conocimiento didáctico del contenido del profesorado (Mora y Parga, 2008).

Como principios de la EA estarían: a) Un enfoque interdisciplinar donde las dimensiones ecológicas, socioeconómicas y socioculturales están combinadas; b) Un punto de vista integral y de cooperación entre lo local / regional / internacional o la mirada "de lo inmediato a lo lejano"; c) capacidad para resolver problemas complejos e identificar valores; d) proporcionar experiencias de primera mano, permitiendo a los estudiantes de todos los niveles educativos tomar sus propias decisiones y responsabilizarse por ellas. Como metas de la EA y sustentados en la Conferencia de Tbilisi, se tienen: a) desarrollar conciencia ambiental comprendiendo las interacciones entre factores económicos, sociales, culturales, políticos y ecológicos; b) inculcar sentido de responsabilidad hacia la calidad del medio ambiente; c) desarrollar comportamientos y actitudes respetuosas con el medio ambiente, así como una disposición a participar de forma efectiva en la conservación y mejora del entrono; d) despertar un sentido de solidaridad entre países y regiones para prevenir y resolver problemas ambientales; y en la educación superior se debería complementar con la adquisición de un conocimiento general en educación ambiental previo a ejercer su actividad profesional.

García-Díaz (2000), plantea que en el plano didáctico y del aprendizaje se requiere de:

> "Un cambio en los procesos cognitivos, desde formas de actuación y de pensamiento implíatas y poco organizadas, hacia otras explíatas, más coherentes y organizadas; desde una visión del mundo focalizada en lo perceptivo, evidente, presente e inmediato (los fenómenos del mesocosmos), hacia una visión basada en el reconocimiento de lo poco evidente, lo inferido $y$ lo posible, y de otros niveles de la organización de la realidad (el micro y el macrocosmos); desde el centramiento en una única perspectiva hacia $e$ l poliperspectivismo $y$ el decentramiento".

> "un cambio epistemológico y ontológico, con la transición desde una concepción aditiva de la organización del mundo hacia formas de pensamiento más sistémicas; desde una causalidad mecánica y lineal hacia el conocimiento de la interacción; desde el predominio de las relaciones dicotómicas y antagónicas hacia la noción de complementaridad; desde una concepción estática y rígida del orden en el mundo hacia otra más flexible basada en el equilibrio dinámico y la evoluciórt'.

> "Un cambio actitudinal, desde el dogmatismo, la intolerancia y la dependencia moral, hacia el relativismo, la tolerancia y la autonomía moral; desde la explotación, el dominio, la imposición y el individualismo, hacia la negociación democrática, la solidaridad y la cooperación; desde el consumismo y la explotación del medio sin límites hacia sistemas de valores más ecológicos".

Existen distintos acercamientos a los métodos de integración del contenido ambiental en la educación superior general. Tanguiane y Perevedentsev (1997) consideran que en la educación secundaria pre-universitaria en general, la opinión predominante es que los temas ambientales deberían ser integrados en el contenido de las distintas disciplinas, pero cuidando que en cada disciplina se traten como entidades independientes sino mas bien en interacción de sus curnículos, lo que supone una transición de visiones analíticas a las sintéticas del conocimiento. En el caso de la educación superior que se caracteriza por la especialización se recomienda un aurso introductorio e interdisciplinar de carácter general para estudiantes de todas las ramas (tanto de ciencias naturales, sociales, letras y las artes) acerca de los principales problemas de las relaciones entre el hombre y el medio ambiente, en esta propuesta no se dice si el carácter debería ser obligatorio o electivo. También se podría pensar en complementar la integración de los temas ambientales en las disciplinas impartidas en las distintas ramas de especialización con un curso interdisciplinar paralelo basado en las principales áreas del conocimiento cientúfico, no representadas como tales en el curnículo de dicha rama de especialización. En otras palabras, podría significar que un curso para estudiantes de ciencias sociales y letras abordańa los temas ambientales desde el punto de vista de 
las ciencias naturales y mostrańa su relación con aspectos socio-económicos, políticos y junídicos y sus puntos en común con las ciencias naturales.

Los conocimientos ambientales necesarios son diferentes para un ingeniero que para un artista, o un futuro profesor de ciencias, por lo que el diseño de estos curríaulos debería ser conjuntamente con los especialistas en cada disciplina. Este tipo de trabajo curricular requiere de trabajo investigativo conjunto entre distintos especialistas provenientes de distintos campos organizados en un grupo de trabajo permanente en el campo aurricular universitario que realicen una evaluación sistemática que contribuyan a mejorar los contenidos, sus citerios de selección, los métodos de integración en las áreas básicas y espećficas de los planes de estudio, así como su impacto ético en los estudiantes. Lo importante es poder determinar en qué lugar de los planes de estudio se debería hubicar estos cursos ambientales como ecología, ética ambiental, educación ambiental, en muchos casos y sobre todo para carreras que no son por su naturaleza ambiental podrían estar ubicadas en los cursos obligatorios complementarios, o en los electivos intrínsecos, mientras que para carreras que son propios de las facultades ambientales, los cursos serían ubicados en los obligatorios básicos, y en los electivos intrínsecos. También es fundamental complementar las propuestas curriculares con cátedras ambientales abiertas ofrecidas entre varios docentes desde un grupo de reflexión colectiva entre docentes y estudiantes en tomo a problemáticas centrales en la constitución de la identidad ambiental de una propuesta curricular permanente y perteneciente varias carreras. Todas estas tendencias han dependido de la formación docente en las concepciones ambientales y de su compromiso en la aplicación y seguimiento de su desarrollo profesional pedagógico / didáctico que se articulan de forma permanente en periodos largos de tiempo de induso varios años a grupos de docentes provenientes de distintas disciplinas y profesiones que se interesan por lo ambiental.

El desarrollo de procesos formativos basado en competencias ambientales son herramientas fundamentales en el diseño ambientalizado de los procesos formativos, sin embargo la lógica seguida en muchas instituciones se conduce desde el sentido de lo obvio en el diseño curricular muchas veces generando confusiones y mayor trabajo del esperado como lo hemos encontrado en nuestra investigación y es muy concomitante a lo reportado por Javier Riojas (2000) y que presentamos en el cuadro adjunto, y que obedece a cinco tendencias que por tradición se han seguido para incorporar lo ambiental desde las carreras de pregrado en las universidades, destacando los alcances y limitaciones: 
TENDENCIAS

Tendencia de resistencia o rechazo

Tendencia adicionista. Sumar uno o varios cursos a los planes de estudio, sin una modificación en la lógica y fundamentos curriculares los cuales no se someten a crítica.

Pretende despertar conciencia y responsabilidad profesionales frente a la problemática ambiental exhortándolos a cambiar las prácticas profesionales o investigativas.

La lógica de operación del cuerpo disciplinar o profesional sigue siendo igual.

Tendencia transversalista. Acorde a las necesidades de comprensión y solución de problemas específicos de una carrera.

Las ciencias naturales y tecnológicas se integran las áreas socio humanísticas, donde lo importante es la articulación ecosistemas sociosistemas.

Tendencia profesionalizante: creación de un programa especializado en lo ambiental.
Consiste en más que anexar cursos o incluir una reflexión ambiental a una

Tendencia integracionista. creación de espacios superiores $\mathrm{e}$ interdisciplinares de reflexión e investigación, entre varias carreras en distintos ciclos de pregrado o postgrado de una o varias facultades.
Sostiene que lo ambiental ya está incluido en el currículo ya que en los planes de estudio existen materias o cursos en estos temas biológicos y / o ecológicos.

Es la estrategia más común de las universidades, que parten de la idea que el problema formativo es la deficiente información de la variable ecológica y ambiental, por lo que basta con la adición de un curso generalista de ecología, de educación ambiental, o de ética ambiental.

Aparecen énfasis tecnológicos centrados en la enseñanza de las 4Rs, las tecnologías limpias, o el punto de vista ético de cambios de valores, comportamiento de los individuos y la calidad de vida. investigación particular aunque estas estrategias coexistan, se dirige a tratar como problemas formativos las posibles situaciones de la profesión, se trabajan desde la dimensión ambiental a lo largo de un espacio de tiempo particularmente de uno $o$ varios semestres.

Creación de carreras ambientales tanto en pregrado o en postgrado formando para la comprensión de los problemas ambientales $y$ en $\mathrm{el}$ conocimiento de los recursos y herramientas técnicas, jurídicas y económicas fundamentales para la solución de los mismos.

No se siente la necesidad ni se es consciente de la necesidad de los temas ambientales como sistema formativo del estudiantado.

\section{Es una visión simplista de la} ambientalización curricular introducción de nuevas asignaturas (prevaleciéndose y estimulándose una visión fragmentada y atomizada del currículo en donde se soslaya los fenómenos locales y los abordajes interdisciplinares), ambientalización de las asignaturas del área básica de ciencias naturales (visión reduccionista en que lo ambiental es sólo tema de biólogos, químicos, físicos). Ofrece la posibilidad no direccionada para que algunos estudiantes integren por si mismos los elementos que conformarían una visión integral de lo ambiental.

Puede presentarse como limitante el que no todos los programas académicos de formación se prestan a un tratamiento complejo e interdisciplinar asociado a la reflexión y discusión epistemológica de los procesos adoptados.

Muchas veces se cae en una visión de lo ambiental desprovisto de los socio humanístico y centrándose en la relación ecología / economía.

Falta de reconocimiento social de estos nuevos profesionales que no lo hacen competitivos frente a otros profesionales que se han dedicado a tratar problemas ambientales.

Creación de de ciclos ambientales o áreas ambientales en los planes de estudio entre varias carreras tecnológicas, profesionales e incluso entre ciclos de postgrado.
Creación de Cátedras abiertas de contexto ambiental donde se reflexiona sobre problemas estratégicos y actuales de una región o una localidad para la cual se convoca a un grupo de docentes coordinadores con la asistencia de toda la comunidad (estudiantes docentes administrativos)

\section{Temáticas de enseñanza en Educación Ambiental}

Los contenidos conceptual, procedimental y actitudinal están articulados a sus respectivas competencias a formar en el estudiantado en un contexto de grandes temáticas. Estos temas deben generar el contexto para tratar uno o varios de los contenidos que se requieren en un plan de estudios en niveles cada vez más amplios y profundos (en tramas evolutivas), en una concepción de curríaulo reaurrente, no lineal sino en espiral, retomando constantemente y a niveles cada vez más superiores los núdeos básicos de cada material, caracterizada como un proceso permanente de reconstrucción y apropiación de conceptos que generan sentidos sobre la sustentabilidad.

Diversas son las posibilidades de selección de temáticas de enseñanza en EA para distintos cursos ambientalizados, ello depende de los distintos intereses y posicionamientos conceptuales de 
los proponentes. Sin embargo es posible establecer unas grandes temáticas que son recurrentes en las recomendaciones dadas en congresos o en publicaciones nacionales e internacionales:

1. Grandes problemáticas mundiales asociadas al ambiente: Tipos de Crisis y la Situación actual de emergencia planetaria. Contaminación, agotamiento de recursos naturales, degradación de ecosistemas, pérdida de diversidad biológica y aultural. Se analizan los problemas de pobreza, violencia, y riesgo vinculadas a problemáticas espeáficas por ejemplo al calentamiento global, destrucción de la capa de ozono, crecimiento desproporcionado de las ciudades vinculada al desplazamiento forzoso, etc.

2. Causas de la Crisis asociadas al Ambiente: Articulación del Modelo Económico Desarrollista a las formas de producción del Conocimiento sustentadas en el Paradigma de la Modernidad (modernidad vs postmodemidad), vinculadas a problemáticas derivadas como el hiperconsumo, la explosión y transición demográfica, las inequidades y desequilibrios humanos, la actividad de las organizaciones mafiosas, la urbanización creciente y desordenada, y la actividad especuladora de empresas transnacionales. También se deben discutir la naturaleza del modelo económico desarrollista y la ciencia modema vinculante al advenimiento de lo que se ha llamado postmodemidad e hipermodernidad.

Es importante tener en cuenta que cada uno de los temas anteriores puede generar desde concepciones educativas hasta simples cursos de enseñanza, por ejemplo, los programas de educación ambiental centrados en reducir el consumo hacen énfasis por ejemplo en las cuatro « $\mathbf{R}$ » reducir el consumo, reutilizar los que ya hemos usado, recidar los productos dándoles otra finalidad, y finalmente, rechazar lo que el marketing propone; 0 aquellos centrados en preocupaciones de gestión ambiental (gestión del agua, gestión de desechos, gestión de la energía, por ejemplo) se asocian a la coniente conservacionista / recursista. Recientemente, la educación para el consumo, más allá de una perspectiva económica, ha integrado más explíatamente una preocupación ambiental de la conservación de recursos, asociada a una preocupación de equidad social, generando un imperativo de acción: comportamientos individuales y proyectos colectivos.

3. La falta de articulación sociedad / naturaleza: el equilibrio dinámico: ecología / economía / socio - humanismo.

Según sea el acercamiento a las dimensiones: económica, antropocéntrica, o ecocéntrica, como de sus distintas hibridaciones tendríamos miradas, desarrollistas, proteccionistas, conservacionistas, o ambientalistas (biocentristas) que determinan no solo los contenidos a enseñar sino también las estrategias de trabajo didáctico del profesorado.

4. Condiciones ecológicas (conservación, capacidad de carga, resilencia, huella ecológica) $y$ termodinámicas (segundo principio) asociadas al desarrollo sustentable:

Los seis principios o criterios operativos y reguladores del desarrollo sostenible que podrían garantizar la "sostenibilidad de las funciones ambientales" en el marco de la idea de Herman Daly (Castiblanco, 2007) del "estado estacionario de la economía", asociado con el objetivo de minimizar el uso de materiales y energía pueden ser un buen contexto de trabajo educativo:

> Principio de irreversibilidad cero: Las intervenciones acumulativas y los daños imreversibles deben reducirse a cero.

$>$ Principio de recolección sostenible: Las tasas de recolección de los recursos renovables deben ser iguales a las tasas de regeneración natural de los mismos.

$>$ Principio de vaciado sostenible En el caso de los reaursos naturales no renovables, la tasa de extracción o explotación debe ser igual a la tasa de creación de sustitutos renovables. 
$>$ Principio de la emisión sostenible Las tasas de emisión de residuos deben ser iguales a las capacidades naturales de asimilación de los ecosistemas, lo que implica emisión cero de residuos no biodegradables.

> Principio de selección sostenible de tecnologías: Se debe favorecer las tecnologías que aumenten la productividad de los recursos, frente a las tecnologías que incrementen la cantidad extraída de recursos (eficiencia frente a crecimiento).

> Principio de precaución Ante la magnitud de los riesgos a que nos enfrentamos y ante los grandes sesgos de información, se debe mantener una actitud vigilante que identifique y descarte todas aquellas intervenciones sobre el medio natural que podrían llevar a desenlaces catastróficos y de carácter irreversible, aunque la probabilidad de éstos parezca pequeña e implique seleccionar altemativas más difíiles y onerosas.

5. Desarrollo Sostenible fuerte y débil: Principios del Desarrollo Humano Sustentable y Tipos de Derechos Humanos. Hay seis principios del Desarrollo Sostenible (Riechmann, 2006:171):

- Precauciónt favorece una aproximación preventiva antes que reparadora. Sostiene que en caso de que existan dudas cient́ficas razonables, reaumir a los procedimientos de evaluación y medidas preventivas pertinentes para evitar los daños a la salud humana y al medio ambiente.

> Solidaridad Sincrónica y Diacrónica (entre todas las poblaciones del mundo y entre las generaciones actuales y futuras): en estrecha conexión con el principio de igualdad social.

> Participación (principio democrático): del conjunto de los actores sociales en los mecanismos de decisión. Aumentando la educación y la sensibilización de los ciudadanos sobre el impacto de su modo de vida en el medio ambiente y las altemativas más sostenibles a su disposición.

$>$ Autocontención: Gestión generalizada de la demanda.

> Biomímesis: Imitación de algunos rasgos destacados de los ecosistemas, que a su vez determina seis criterios básicos de sustentabilidad ecológica de la economía (estado estacionario en términos biofísicos, vivir del sol como fuente energética, cerrar los cidos de materiales, no tansportar demasiado lejos los materiales, evitar los xenobióticos como COP (contaminantes orgánicos persistentes), OMG (organismos transgénicos)..., respetar la diversidad).

> Ecoeficienciar minimizar el impacto ambiental por unidad del producto. Por ejemplo duplicando la satisfacción de las necesidades humanas reduciendo a la mitad el consumo de recursos naturales y el consiguiente impacto ambiental.

6. Bases epistemológicas del Conocimiento Sistémico como respuesta a los problemas ambientales desde una nueva concepción del mundo reformuladora del saber: Sistemismo, complejidad, constructivismo, hermenéutica y teoría crítica.

Hablar de indusión de la dimensión ambiental tiene que ver con un Contexto Sistémico como lo diría Garciandía (2005), articulando cibernética (causalidad circular), con constructivismo (concepción de la realidad), hermenéutica (lenguaje y arte de la interpretación), y complejídad (método de pensar sistémico), y adicionalmente ética, $y$ estética, entre otros aspectos que tendrían que ser tratados en los currículos ambientales en las especificaciones propias de cada cultura. El análisis sistémico permite identificar los diferentes componentes de un sistema ambiental y de poner en relieve las relaciones entre sus componentes, entre las cuales las relaciones entre los elementos biofísicos y los elementos sociales de una situación ambiental. El estudio de un medio ambiente dado lleva primeramente a la identificación de los siguientes aspectos: los elementos del sistema, es decir los actores y factores (incluso humanos) aparentemente responsables de un estado (o de un cambio de estado); las interacciones entre estos elementos (la sinergía por ejemplo o los efectos contradictorios); las estructuras en las cuales los factores (o los seres) intervienen (induyendo las fronteras del sistema, las redes de transporte y de comunicación, los depósitos o lugares de almacenamiento de materias y de energía); las reglas o las leyes que rigen la vida de estos 
elementos (flujos, centros de decisión, cadenas de retroacción, plazos, etc.). En un segundo tiempo, se trata de comprender las relaciones entre estos diversos elementos y de identificar por ejemplo las relaciones causales entre los acontecimientos que caracterizan la situación observada. Finalmente, se puede aprovechar la comprensión sistemática de la situación estudiada para la búsqueda de soluciones menos perjudiciales o más deseables respecto al medio ambiente.

7. Paradigmas emergentes del saber ambiental: Teorías del Caos, Gaia, Fractales, etc. Estos cambios sustentados fundamentalmente en la Complejidad se uniría a otras teorías como:

\begin{tabular}{|l|l|}
\hline \multicolumn{1}{|c|}{ TEORÍA } & \multicolumn{1}{c|}{ CARACTERISTICAS } \\
\hline $\begin{array}{l}\text { La teoría de la } \\
\text { catástrofe }\end{array}$ & $\begin{array}{l}\text { Los sistemas sufren cambios repentinos de manera discontinua, de varias respuestas posibles que } \\
\text { no se pueden predecir a priori sino que son un accidente de varias circunstancias. }\end{array}$ \\
\hline La Teoría del Caos & $\begin{array}{l}\text { La predicción no es posible por la acumulación de pequeñas interacciones entre los componentes, } \\
\text { por esto no se puede pronosticar el dima con precisión. }\end{array}$ \\
\hline $\begin{array}{l}\text { Teoría de los } \\
\text { Fractales }\end{array}$ & $\begin{array}{l}\text { Teoría mandelbrotiana cuya concepción hologramática (bucle recursivo) está llevando a creer que } \\
\text { el "todo está en las partes que están en el todo". }\end{array}$ \\
\hline $\begin{array}{l}\text { La teoría de la } \\
\text { jerarquía }\end{array}$ & $\begin{array}{l}\text { El universo es un todo organizado en niveles (holones) o escalas de organización ascendentes en } \\
\text { complejidad que son a su vez subsistemas que miran en direcciones opuestas (autonomía / } \\
\text { dependencia; reduccionismo / holismo). }\end{array}$ \\
\hline Hipótesis Gaia. & $\begin{array}{l}\text { Sostiene que la evolución de los organismos está atada a la evolución del medio físico, donde la } \\
\text { Tierra se autorregula como un ser vivo. }\end{array}$ \\
\hline $\begin{array}{l}\text { La termodinámica de } \\
\text { los sistemas abiertos. }\end{array}$ & $\begin{array}{l}\text { Permite explicar los sistemas auto-organizados así los sistemas naturales tienden a resistir a la } \\
\text { separación del equilibrio, respondiendo espontáneamente disipando energía. }\end{array}$ \\
\hline
\end{tabular}

\section{El Pensamiento Ambiental como Diálogo de Saberes: Más allá de la interdisciplinariedad.}

El pensamiento ambienta/se configura en una epistemología de diálogo de saberes (Leff, 2006) en la cotidianidad del mundo de la vida en la que los problemas ambientales se dan en relación dialéctica con los sistemas cultural /ecosistema, simbólico /biótico, en el mundo actual se presentan más acusados en lo cultural. Más que en un campo interdisciplinar en donde los saberes populares se hacen fundamentales, este dialogo por ejemplo, se fundamenta en la necesidad de un conocimiento como el tecnológico que ha sido entendido en las aulas de clase como ciencia aplicada y subordinado a ella, le ha generado un estatus de inferioridad que supedita todo aspecto práctico a lo teórico y en gran medida ha afectado conceptualmente al saber tecnológico al suponer que los resultados de reflexión de la naturaleza de las ciencias son suficientes y trasplantables a la tecnología (Mora, 2007a, 2007b).

9. La Interdisciplinariedad implica voluntad y compromiso de elaborar un marco más general en que cada una de las disciplinas en contacto son a la vez modificadas y pasan a depender claramente unas de otras. Aquí se establece una interacción entre dos o más disaiplinas, lo que da como resultado un intercambio y enriquecimiento recíproco $y_{r}$ en consecuencia, una trasformación de sus metodologías de investigación, una modificación de conceptos, de terminologías fundamentales, etc. La Transdisciplinariedad es el nivel superior de interdisciplinariedad, de coordinación, donde desaparecen los límites entre las distintas disciplinas y se constituye un sistema total que sobrepasa el plano de las relaciones e interacciones entre las disciplinas. La cooperación es tal que puede hablarse de la aparición de una nueva macrodisciplina, como el campo de las sistémica, complejidad, ecología, ambiente (Torres, 2006).

Rolando García (2006) dice que llamará "investigación interdisciplinaria al tipo de estudio que requiere un sistema complejd" y que "lo que integra a un equipo interdisciplinario para el estudio de un sistema complejo es un marco conceptual y metodológico común, derivado de una concepción compartida de la relación ciencia - sociedad, que permitirá definir la problemática a estudiar bajo un mismo enfoque, resultado de la especialización de cada uno de los miembros del equipo de investigación'. En esta actividad la interdisciplinariedad depende de la existencia de las 
especializaciones disciplinares, por lo que se oscila entre dos extremos radicales, la especialización absoluta y la generalidad excesiva (diferenciación / integración que tienen lugar en el proceso que conduce a la definición y estudio de un sistema complejo en el diagnóstico de sus raíces ya sea para prevenirlos o generar políticas que detengan o reviertan el deterioro encontrado).

10. Ética Ambiental y Calidad de Vida: orientada a la formación en valores y comportamientos sociales hacia los objetivos de sustentabilidad ecológica y equidad social.

Siguiendo la idea Van Potter (Maldonado y otros, 2002) la bioética es una ciencia de la vida y de la complejidad que nos permite entender y plantearnos aquello que hace posible la vida, (como proceso evolutivo constante a través de contingencias de adaptación flexibles de grandes poblaciones en una red de redes de interdependencia compleja en la que todo lo que la constituye se hace esencial), y las formas de perpetuarse y no de extinción, comprometiendo el conocer con el actuar más allá de la obediencia de las leyes, escogiendo el futuro de mundo planetario deseable. Bajo una visión biocéntrica / ecocéntrica e interdisciplinar la bioética viene teniendo relaciones muy estrechas con la ética de las disciplinas y áreas espećficas del conocimiento, como por ejemplo la tecnología y la ingeniería (Mora, 2008b) integrándose a la reflexión / acción de temas y problemáticas ecológicas y medio ambientales como instancia crítica del desarrollo sostenible en una macro bioética o bioética global, como lo diría Maldonado y otros (2000) que va más allá de una ética aplicada vinculada únicamente hacia las ciencias de la salud, la biotecnología, y al control de tribunal de la investigación cientúfica; y sí, más centrada en los grandes problemas que afectan las colectividades humanas en relación a los ecosistemas globales y locales, a la supervivencia, el riesgo y la buena vida en general. Rubiel Ramírez Restrepo (Noguera, 2007), en su libro "Ética Ambiental: parámetros para un discusión" (1998), propone tres elementos daves y bases para una ética ambiental: la libertad, la responsabilidad y la solidaridad. La libertad de tomar decisiones sin coacción parte de una condición no condicionada: la naturaleza, si el hombre sabe interpretar la naturaleza, obrará libre y responsablemente, y la solidaridad implica de un lado el respeto por los límites y de otro, aceptar que tenemos un destino común con la naturaleza.

\section{Conclusiones}

Se ha intentado mostrar como la dimensión ambiental, articulada a la situación de crisis y emergencia planetaria, se encuentra entre las prioridades educativas más importante en todo el mundo. Sin embargo y a pesar de existir una legislación, particularmente en Colombia, orientada a adecuar los procesos formativos en las instituciones educativas en todos los niveles, la situación de trasformación de las prácticas educativas no parece ser las más deseables. La situación se contextualiza en varios factores como la falta de madurez del campo disciplinar de la educación ambiental, si se compara con la comunidad de investigadores en enseñanza de las ciencias, y de la falta de curnículos formativos para el profesorado que vinculen daramente las relaciones sociedad naturaleza en sus planes de estudio desde una perspectiva inter y transdisciplinar, que analicen el conocimiento desde la complejidad, el constructivismo, la visión crítica y hermenéutica de los significados.

Las necesidades de procesos formativos del profesorado que demandan la acreditación e internacionalización de los curníalos, mecanismos de flexibilidad, el uso de las TICs, bajo la demanda de citerios formativos de recidaje permanente de los conocimientos a lo largo de toda la vida del profesional de la educación, se argumentan como base adicional para lograr una enseñanza más allá de la transmisión de conocimientos dogmatizados y acabados, y más dedicada al diseño de espacios de aprendizaje que permitan la participación en la resolución de problemas socialmente pertinentes. 
La inclusión de la dimensión ambiental en los procesos formativos en la educación superior se puede decir que requiere de análisis crítico, dada la falta de interés de muchos profesores universitarios por la investigación de los temas ambientales articulados a la generación de propuestas pedagógicas y didácticas más allá de las propias de política o gestión sobre el medio ambiente. Las mismas universidades no están preparadas para estos retos, así la departamentalización administrativa de las facultades y la super especialización de las áreas de conocimiento dificultan alianzas e integraciones entre docentes para generar propuestas formativas de carreras ambientales. También es daro que entre los aspectos misionales de la mayoría de las universidades no contemplan los temas ambientales y de sustentabilidad, patrocinados si se quiere por la falta de indicadores ambientales en sus procesos de autoevaluación y acreditación, máxime que el CNA (Consejo Nacional de Acreditación) no los exige, lo cual es una debilidad si se compara con las exigencias hechas, a las Universidades adscritas al acuerdo de Bolonia del Espacio Europeo de Educación superior.

Las Universidades se ven avocadas a ambientalizarse, no sólo en sus procesos de manejo de la gestión y el saneamiento básico de su planta física sino en sus procesos misionales de docencia, investigación y extensión. En lo que compete a la docencia no basta con incluir cursos de ecología, economía, o ética ambiental, se requiere transversalizar los curnículos, y principalmente generar propuestas formativas de pregrado y postgrado. Para esto se requiere tener muy daro el tipo de competencias ambientales que se quiere formar, para de esta manera proponer los procesos formativos requeridos y la selección de contenidos que se requieren en la formación inicial y permanente del profesorado.

\section{Bibliografía}

Acevedo, José., Vázquez, Ángel., y Manassero, Mańa. (2003). El Movimiento Ciencia - Tecnología Sociedad y la Enseñanza de las Ciencias. Reauperado el 20 de marzo de 2005, de http://unw.campus-oei.org/salactsi/acevedo13.htm

Ángel, Augusto. (1995). La Fragilidad Ambiental de la Cultura. Editorial Universidad Nacional. Instituto de Estudios Ambientales, Bogotá.

Aznar, Pilar (2006). El Reto Educativo de la Sostenibilidad en el marco del Espacio Europeo de la Educación Superior. [En: Escolano, Agustín (2006). Educación Superior y Desarrollo Sostenible Madrid: Biblioteca Nueva. pp. 168-187].

Aznar, Pilar y Ull, Ma Angels (2009). La formación de competencias básicas para el desarrollo sostenible: el papel de la Universidad. Revista de Educación, número extraordinario, 2009, pp. 219-237.

Benayas, Javier., Gutiérrez, José., y Hemández, Norma. (2003). La Investigación en Educación Ambiental en España. Madrid: Ministerio de Medio Ambiente - Parques Nacionales.

Cañal, P. (2004). La alfabetización científica: ¿Necesidad o Utopía? Cu/tura y Educación, 2004, 16 (3), 245-257.

Caride, José, Meira Pablo. (2001). Educación Ambiental y Desarrollo Humano. Barcelona: Ariel Educación.

Carrizosa, Julio., (2003). Colombia de lo Imaginario a lo Complejo. Reflexiones y Notas sobre Ambiente, Desarrollo y Paz Bogotá (Colombia): IDEA - UN.

Clarke D, \& Hollingsworth H. (2002). Elaborating a model of teacher professional growth. Teaching and Teacher Education. 18 947-967.

Castiblanco, Carmenza. (2007). La economía ecológica: Una disciplina en busca de autor. Gestión y Ambiente. 10 (3) pp 7-22 Universidad Nacional de Colombia - IDEA.

Escotet, Miguel A. (2004). Globalización y Educación Superior: Desafíos en una Era de Incertidumbre. [En: ICE- Universidad de Deusto (2004). Pedagogía Universitaria: Hacia un espacio de aprendizaje compartida. III Symposio Iberoamericano de Docencia Universitaria. Vol I. pp. 23-35]. 
García, Rolando. (2006). Sistemas Complejos. Conceptos, método y fundamentación epistemológica de la investigación interdisciplinaria. Barcelona: Gedisa.

Garciandía, José A. (2005). Pensar Sistémico. Bogotá: Pontificia Universidad Javeriana.

García-Díaz, Eduardo. (1998). Hacia una Teoría Altemativa sobre los Contenidos Escolares. Sevilla: Diada Editora.

García-Díaz, Eduardo. (2000). Educación ambiental y Ambientalización del Cumíaula. En: Perales, F.J., y Cañal de León, P. (Compiladores) (2000). Didáctica de las Ciencias Experimentales. pp. 585-613. Madrid: Marfil.

García-Díaz, Eduardo. (2004). Educación Ambiental, Constructivismo y Complejïdad Sevilla: Diada Editora.

García-Díaz, Eduardo. (2006). Educación Ambiental y Alfabetización Cientíica: argumentos para el debate. Investigación en la Escuela. 2006 (60), pp. 7-19.

Gutiérrez, José. (2002). Grados de libertad y enfoques autóctonos de la investigación en educación ambiental. Investigación en la Escuela 2002 (46), pp. 27-39.

Hanna, Donald E. (ed.) (2002). La Enseñanza Universitaria en la Era Digital. Barcelona: OCTAEDRO - UAB.

Junyent, Mercé,, Geli Anna., y Arbat, Eva (Edit) (2003). Ambientalización Cumiaular de los Estudios Superiores 2 Procesos de Caracterización de la Ambientalización Curricular de los Estudios Universitarios. Girona: RED ACES - alfa.

Leal F. Walter (2009). La educación para la sostenibilidad: iniciativas internacionales. Revista de Educación, número extraordinario 2009, pp. 263-277.

Leff, Enrique (Coord.) (2000). La Complejïdad Ambiental. México: Siglo XXI Editores. pp 7 - 53.

Leff, Enrique. (2002). Saber Ambiental. Sustentabilidad, Racionalidad, Complejidad, Poder: México: Siglo XXI Editores - PNUMA.

Lujan, J.L, y Echeverría, J., (Eds) (2004). Gobemar los Riesgos. Ciencia y Valores en la Sociedad del Riesgo. Madrid: OEI - Biblioteca Nueva.

Luzzi, Daniel (2000). La "Ambientalización" de la educación formal. Un diálogo abierto en la complejidad del campo educativo. [En: Leff, Enrique (Coord.) (2000). La Complejidad Ambiental. México: Siglo XXI Editores. pp 158 - 192]

MMA: Ministerio del Medio Ambiente, y Ministerio de Educación Nacional. (2002). Política Nacional de Educación Ambiental SINA Bogota, D.C.

MEN, (2004). Estándares Básicos de Competencias en Ciencias Naturales y Ciencias Sociales. Formar en ciencias: el desafío. Lo que necesitamos saber y saber hacer. Serie Guías № 7. Bogotá: MEN.

Maldonado, Carlos E. y otros (2000). Bioética y Medio Ambiente. Bogotá: Universidad del Bosque. Editoral Kimbres Ltda. Colección Bios y Ethos.

Maldonado, Carlos E. y otros (2002). Fundamentación de la Bioética. Una tarea Común. Bogotá: Universidad del Bosque. Editoral Kimbres Ltda. Colección Bios y Oikos 1.

Mora W. M., Garća A., y Mosquera C.J. (2004). Estrategias para el Desarrollo Profesional en el Campo Pedagógico y Didáctico del Profesorado de Ciencias Experimentales y tecnologías a Nivel Universitario. [En: ICE- Universidad de Deusto (2004). Pedagogía Universitaria: Hacia un espacio de aprendizaje compartido. III Symposio Iberoamericano de Docencia Universitaria. Vol II pp. 1563-1580].

Mora, William y Parga, Diana. (2005). Evaluación por competencias y estándares de competencia, en el campo de la enseñanza de las ciencias y educación ambiental. Revista: Enunciación. № 10. pp. 73-84. (Universidad Distrital - Bogotá).

Mora, William M. (2007). Respuesta de la universidad a los problemas socio - ambientales: La ambientalización del currículo en la educación superior. Revista: Investigación en la Escuela. (Sevilla - España). 2007. 63 (3), pp. 65-76.

Mora, William M. (2008a). Indusión de la Dimensión Ambiental en la Docencia de la Facultad de Medio Ambiente y Reaursos Naturales Universidad Distrital Francisco José de Caldas. (pp. 5567). [En: Bermúdez, Olga (Comp.) (Agosto, 2008). Memorias de los Foros Ambientales 2006 2007). Red temática de educación ambiental. Bogotá: IDEA - UN]. 
Mora, William M. (2008b). Ética, Dimensión Ambiental y Cumíaulos de Formación de Ingenieros. Ponencia Oral (T4-015). XXVIII Reunión Nacional de ACOFI: Las facultades de ingeniería y su aporte al desarrollo del país. Cartagena de Indias, 18 de septiembre de 2008.

Mora, William M (2008c). Elementos para la articulación de principios formativos basados en competencias en la Universidad Distrital Francisco José de Caldas. Bogotá: Comité Institucional de Currículo. Documento de trabajo. Noviembre de 2008.

Mora, William y Parga, Diana. (2008). El Conocimiento Didáctico del Contenido en Química: Integración de las Tramas de Contenido / histórico - epistemológicas con las tramas de Contexto / Aprendizaje. En Revista: Tecné, Epistemé y Didaxis (TED) № 24, pp. 54-74. Bogotá: UPN. http: //Www.pedagogica.edu.co/revistas/ojs/index.php/TED.

Morin, Edgar. (2000). Introducción al Pensamiento Complejo. Barcelona: Gedisa Editorial.

Noguera, Ana P. (2007). Complejidad ambiental: propuestas éticas emergentes del pensamiento ambiental latinoamericano. Gestión y Ambiente 10 (4) pp 5-30. Universidad Nacional de Colombia - IDEA. http: //uww.revistas.unal.edu.co/index.php/gestion/artide/view/1156/1969

Novo, María (2003). La Educación Ambiental, Bases Éticas, Conceptuales y Metodológicas. Madrid: Editorial Universitas. S.A.

Novo, María (2009). La Educación Ambiental una Genuina Educación para el Desarrollo Sostenible. Revista de Educación número extraordinario 2009, pp. 195-217.

OEI - Educadores por la sostenibilidad, (2009). ¿Crisis Financiera o Crisis Global? La Economía Verde como necesidad y oportunidad. Boletín № 32, 15 de enero de 2009. Década por una Educación para la Sostenibilidad. http://uww.oei.es/decada/boletin032.htm. Rev. Eureka, 2009, 6(2), pp. 315-316. http://uww.apac-eureka.org/revista.

Riechmann, Jorge. (2006). Biomímesis. Ensayos sobre imitación de la naturaleza. Ecosocialismo y Autocontención. Madrid: Los Libros de la Catarata.

Riojas, Javier (2000). La Complejidad Ambiental en la Universidad. [En: Leff, Enrique (Coord.) (2000). La Complejïdad Ambiental. México: Siglo XXI Editores. pp 193 - 215]

Sanmartí, N. (2004). Proyecto investigador: La enseñanza de la modelización en ciencias, educación ambiental y argumentación. Universidad Autónoma de Barcelona. pp 47-61.

Santos, Miguel., y Guillaumín, Arturo (2006). Avances en Complejidad y Educación: Teoría y Práctica. Barcelona: OCTAEDRO S.L.

Sauvé, Lucie (2004): "Uma cartografía das correntes em educação ambiental". En Sato, M. y Carvalho, I (coord.): Educacão Ambiental: pesquisa e desafios Porto Alegre: Artmed, pp. 17-44. (Una cartografía de corrientes en educación ambiental) http://umw.scribd.com/doc/13011956/Cartografia-de-Comientes-de-Educacion-Ambiental. (11Junio-2009).

Sauvé, Lucie. (2006). La Educación Ambiental y la Globalización: Desafíos Curriculares y Pedagógicos. Revista Iberoamericana de Educación. 41. pp 83 - 101.

Tanguiane, S., y Perevedentsev, V. (1997). Criterios Pedagógicos y Científicos para definir el Contenido Ambiental de la Educación Universitaria. Madrid: UNESCO - PNUMA. Los libros de la Catarata.

Torres, Jurjo. (2006). Globalización e Interdisciplinariedad; el aumíaulo integrado. Madrid: MORATA. Quinta edición.

Torres, Maritza. (1996). La Dimensión Ambiental: Un reto para la educación de la nueva sociedad. Bogotá: MEN.

Selby, D. (1996). Educación global: Hacia una irreductible perspectiva global en la escuela. AULA de Innovación Educativa, 51, 25-30.

Yus, R. (1997). Hacia una educación global desde la transversalidad. Madrid: ANAYA S.A.

Vílches, Amparo., y Gil, Daniel. (2003). Construyamos un Futuro Sostenible. Diálogos de Supervivencia. Madrid: OEI - Cambridge. 